Psicobiologia e Psicologia Cognitiva

\title{
Valores humanos como moderadores e supressores na preferência do consumidor por marcas e produtos
}

\author{
Rafael Barreiros Porto \\ Cláudio V. Torres \\ Universidade de Brasília
}

\begin{abstract}
Resumo
Alguns estudos presumem que a predição dos valores humanos sobre as escolhas dos consumidores é mediada pelas atitudes dos produtos, todavia não testam se eles são moderadores dessa relação e supressores da escolha anterior. A moderação e supressão seriam prováveis ao observar a qualidade e o grau das intensificações ou atenuações dos valores nas decisões e nas inércias das escolhas, não pressupondo serem causas delas. Efetuaram-se testes de interação dos valores junto à importância dos critérios de decisão para predizer preferência por produtos e marcas, considerando a escolha anterior. As regressões logísticas e ordinais demonstram que os valores humanos moderam a relação decisões -preferência e suprimem a influência inercial da escolha anterior com bons ajustes e poderes preditivos. Os resultados auxiliam a compreender o papel dos valores humanos nas escolhas dos consumidores.
\end{abstract}

Palavras-chave: valores humanos; moderação; supressão; decisão do consumidor; preferência declarada.

\begin{abstract}
Humans values as moderators and suppressors of consumer's preference for brands and products. Some studies assume that the prediction of human values on consumer choices is mediated by the attitudes of the products, but do not test if they are moderators of this relation and suppressors of the previous choice. The moderation and suppression would be likely observing the quality and level of intensification or attenuation of the values on decisions and on the inertia of choices, assuming they are not causes of them. We performed interaction tests of values with the importance of decision criteria to predict preference for products and brands, considering the previous choice. Logistic and ordinal regressions reveal that human values moderate the decisions regarding preference and suppress the inertial influence of previous choice with good fit and predictive power. The results help to understand the role of human values on consumer choices.
\end{abstract}

Keywords: human values; moderation; suppression; consumer decision; stated preference.

\section{Resumen}

Valores humanos como moderadores y supresores de preferencia del consumidor por marcas y productos. Algunos estudios suponen que la predicción de los valores humanos en las opciones del consumidor es mediada por las actitudes de los productos, pero no prueban si son moderadores de esta relación y supresores de la opción anterior. La moderación y la supresión serían probables observando la calidad y el grado de intensificación o atenuación de los valores en las decisiones y la inercia de las opciones, suponiendo que no son las causas de ellas. Realizamos pruebas de interacción de los valores con la importancia de los criterios de decisión para predecir la preferencia por los productos y marcas, teniendo en cuenta la opción anterior. Regresiones logísticas y ordinales demuestran que los valores humanos moderan las decisiones con respecto a la preferencia y eliminan la influencia de inercia de la opción anterior, con buenos ajustes y poderes predictivos. Los resultados ayudan a entender el papel de los valores humanos en las decisiones de consumo.

Palabras clave: valores humanos; moderación; supresión; decisión de los consumidores; preferencia declarada.

$\mathrm{O}$ s estudos sobre os valores humanos foram intensificados no Brasil (Jesuíno, Torres, \& Teixeira, 2012; Tamayo \& Porto, 2005), em especial na área organizacional (Ferreira, Fernandes, \& Silva, 2009; Gouveia, Milfont, Fischer, \& Coelho, 2009) e em consumo (Jesuíno et al., 2012; Torres \& Allen, 2009). Nesta última área, o modelo de Schwartz (1992) é um dos mais testados empiricamente, mas com baixo poder preditivo ( $R^{2}$ máximo e raro de $\left.26 \%\right)$ sobre as escolhas e preferências de consumo (Alfinito, 2009; Fortes, 2006; Maduro-Abreu \& Brasil 2013). Isso se deve a dois equívocos nos métodos de investigação dos valores. Um referente à sua concepção como variável antecedente às escolhas, 
sendo geralmente mediada pelas atitudes (ou avaliações) e o outro referente à omissão do comportamento anterior nos modelos de teste. O presente estudo oferece uma alternativa metodológica para superação desses equívocos. Ele visa testar a moderação/supressão dos valores sobre a relação preditiva das avaliações (importância dos critérios de decisão) sobre a preferência de marcas e produtos, considerando o comportamento passado (escolha anterior).

O processo de ligação dos valores com o comportamento é formado por meio de sua ativação (Verplanken \& Holland, 2002). A situação ativa um valor na memória quando há escolhas conflitantes pelos indivíduos. Isso leva à concepção de que o comportamento é causado pela busca de congruência com esse valor. O indivíduo passa a perseguir, ou planejar (Gollwitzer, 1996), comportamentos em prol dessa meta abstrata.

Apesar de os estudos serem geralmente correlacionais ( $\mathrm{Ta}-$ mayo \& Porto, 2005), a noção de causalidade permeia as discussões dos resultados dos valores por relacioná-los às teorias das necessidades (Bilsky, 2000). A crença de que uma determinada ação leva ao resultado esperado abstrato pode induzir à atratividade de um valor (Feather, 1988) e quando indagados, indivíduos atribuem como causa a busca dele.

Rohan (2000) sugere que os valores humanos oferecem justificativas às ações, auxiliam a explicação e promovem a decisão comportamental. Segundo o autor, eles são possíveis causas do comportamento, principalmente em situações de escolhas que tenham que ser decididas e justificadas. Com isso os valores pessoais nos estudos empíricos são variáveis antecedentes primárias e visam encontrar alguma evidência de suas influências em comportamentos ou proxys de comportamentos, como as intenções comportamentais (Ma \& Lee, 2012).

A mediação da atitude [Valor-Atitude-Comportamento (Allen \& Ng, 1999)] é investigada geralmente via o Modelo do Comportamento Planejado (Ajzen, 2012) ou suas derivações. Contudo, geralmente os estudos empíricos sobre os valores humanos não testam ou não têm uma compreensão dos mecanismos de influência das decisões comportamentais no contexto (Foxall, 2005). Assim, os autores não clarificam que relações existem entre as decisões, escolhas e valores.

Os avanços têm ocorrido no sentido de demonstrar uma estrutura consistente dos valores humanos (Schwartz, 2011). Há muitos autores que propuseram uma estrutura de valores que pudesse explicar as ações humanas (Hofstede, 2001; Kahle \& Kennedy, 1989; Kluckhohn \& Strodtbeck, 1961; Rockeach, 1973), mas muitos não são aplicados às decisões de consumo ou carecem de validações empíricas consistentes (transculturais e aplicações aos diversos comportamentos) para predizer escolhas comportamentais.

A estrutura validada empiricamente em inúmeras culturas que tem sido mais pesquisada no nível individual é a de Schwartz (1992). Por meio de um continuum circular, que varia entre duas dimensões (abertura à mudança/conservadorismo e autopromoção/autotranscendência), Schwartz (1996) propõe que alguns valores são adjacentes e outros opostos. Quando há conflito entre os valores para o indivíduo é que eles podem ser ativados e serem as causas ou justificativas do comportamento (Tamayo \& Porto, 2005).

Essa estrutura foi atualizada por Schwartz et al. (2012) demonstrando haver fontes que sustentam a ordem entre os valores adjacentes e opostos. Nela, alguns dos 10 tipos motivacionais da estrutura original, se subdividem em tipos motivacionais mais específicos (19 ao todo) que oferecem a orientação motivacional e provém melhor ajuste entre a composição dos valores. Assim, questões referentes à estrutura motivacional parecem ser cada vez mais equacionadas (Schwartz, 2011).

\section{Processo de ligação: valores humanos, decisão e preferência de marcas e produtos}

Os estudos realizados por Schwartz têm encontrado evidências de que as escolhas obedecem à lógica circular do continnum (Jesuíno et al., 2012). No entanto, a ligação com o comportamento de consumo é baixa (Alfinito, 2009; Fortes, 2006; Maduro-Abreu \& Brasil 2013) possivelmente porque os pesquisadores geralmente não testam as situações de conflito entre as decisões de escolha e o que o indivíduo fez ou que escolha ele previamente fez. As escolhas de produtos ou marcas podem refletir a percepção do alcance dos valores (Verplanken \& Holland, 2002), mas elas não são claramente detalhadas nos estudos de valores humanos.

Por um instante, um indivíduo pode estar em um contexto que o restrinja a ter muitas alternativas. Caso escolha uma ação a ser executada, ela pode não refletir o valor endossado. Em consumo, é comum haver esse tipo de situação, onde os produtos ou a marcas desejadas não podem ser adquiridos por terem um alto custo ou por não estarem disponíveis. Nesse sentido, mesmo se o valor for central para o consumidor e mesmo se salientado na situação de escolha (Tamayo \& Porto, 2005), o contexto econômico impede a escolha da marca ou produto se relacionar com o valor endossado por ele. Logo, os valores não são as causas de sua escolha. O que aparenta ser a causa está na situação (Foxall, 2005) e as avaliações das decisões parecem ser as verdadeiras variáveis antecedentes (Bettman, Johnson, \& Payne, 1991; Payne, Bettman, \& Johnson, 1992).

Entretanto, ao adquirir um produto não relacionado com o valor endossado, a busca pela alternativa que pode levar ao alcance do valor ainda continua (Allen \& $\mathrm{Ng}$, 1999), incluindo uma busca por situações facilitadoras (ex; pagar parcelado). Quando encontrar essa situação, os valores podem ser bastante influentes (Verplanken \& Holland, 2002). Assim, os valores ocasionalmente se relacionam com as escolhas de produtos ou marcas, mas outras vezes não. Nas situações relacionadas, o consumidor precisa ter condição de escolher qualquer alternativa e esta não pode ter impeditivo. De forma simulada isso pode ser feito por meio de questões em surveys, onde o consumidor sinaliza quais marcas ou produtos compraria, sem, no entanto, comprar. Portanto, qualquer restrição significativa é eliminada da situação de escolha. 
Estando os valores relacionados às escolhas, este trabalho não pressupõe que os valores são seus antecedentes e nem pressupõe que as decisões (atitudes) medeiam a relação valores-escolha. Mas, propõe que as avaliações dos critérios de decisão podem ser seus imediatos antecedentes (Payne, Bettman, \& Johnson, 1992) e os valores humanos (Schwartz, et al., 2012) podem intensificar ou atenuar a preponderância de um critério ou outro na escolha.

Entretanto, os estudos empíricos em consumo ainda não testaram se os valores são moderadores (Jose, 2012) dos critérios de decisão nas escolhas. Seria esperado que as decisões fossem moderadas pelos valores ao observar a qualidade e o grau das intensificações deles nas escolhas, não pressupondo serem suas causas. Assim, os valores seriam fundamentais para dar importância aos critérios de decisão sem, contudo, causar diretamente a escolha. Como a escolha de marca e de produto podem ter importâncias diferentes, priorizou-se testar tanto em situações de escolha de marca, que geralmente carregam significados mais específicos, quanto em produtos, que carregam significados mais gerais (Allen \& Ng, 1999). Daí deriva-se a primeira hipótese do trabalho.

$H_{1}$ : Os valores humanos moderam a relação da atribuição de importância dos critérios de decisão na preferência por marcas e produtos. Em compensação, um indivíduo pode ter um histórico de ter realizado um comportamento de consumo (ex; comprar uma marca) e essa escolha prévia influencia a próxima ação devido aos mecanismos de atração ou repulsão à alternativa já adquirida (Fishbein \& Ajzen, 1975). A escolha passada não é causa isolada (ou única) de comportamentos subsequentes (Foxall, 2005), mas pode ser indicador preditivo sob certas circunstâncias, porque sinaliza a experiência em contextos previamente expostos e são proxys do comportamento regularmente realizado.

Se os valores humanos atribuem importância para os critérios de escolha, dando-lhes peso (grande ou pequeno) sobre a alternativa a ser escolhida ( $H_{1}$ confirmada), isso pode alterar o peso inercial da escolha passada (Foxall, 2005). Ou seja, se a escolha anterior não cumpre as metas pessoais do indivíduo no tempo presente, os valores podem anular o efeito da inércia do comportamento por meio do peso maior na importância de critérios avaliativos que conduzam às alternativas compatíveis com os valores endossados. Por outro lado, se a escolha anterior já cumpre as metas pessoais do indivíduo no tempo presente, os valores podem ainda sim anular o efeito da inércia do comportamento, mas por meio da saliência de critérios avaliativos que conduzam às alternativas similares, compatíveis com os valores endossados. Dessa maneira, a moderação dos valores humanos sobre a relação de atribuição de importância dos critérios de decisão na preferência por marca e produtos pode suprimir a escolha anterior. Deriva-se assim a segunda hipótese.

$\mathrm{H}_{2}$ : os valores humanos suprimem o efeito inercial da escolha anterior se eles forem moderadores da relação decisão-preferência por marcas e produtos. Para testar as hipóteses desse trabalho, um estudo com teste de moderação e supressão (Jose, 2012) foi proposto com o fim de predizer futuras escolhas desejadas (preferidas). A inserção das avaliações baseadas em critérios e da escolha anterior nos modelos empíricos pode revelar a ligação entre os valores e a preferência comportamental se feitos alguns ajustes metodológicos na concepção dos valores. Este estudo considerou esses arranjos.

A pesquisa fez uso de uma situação de consumo no segmento automotivo. Esse segmento possibilita haver inúmeras alternativas de escolhas de marcas (montadoras automotivas) e até subtipos de produto de carro (sedan luxuoso, utilitário esportivo, compacto luxuoso) baseados em vários critérios avaliativos devido à variedade de modelos e atributos. Além disso, essa variedade permite que haja metas abstratas associadas à busca de um carro novo. O indivíduo pode trocar uma marca ou tipo de carro por outra (o) em busca dessa meta ou mantê-la (o) se já tiver alcançado sua meta. Como alguns indivíduos têm algumas marcas e/ou modelos de carro, futuros modelos (ou marcas) podem refletir busca de metas. Dessa forma, visou-se analisar a preferência por marcas e tipos de carro na qualidade de ser uma medida da escolha subsequente.

\section{Método}

\section{Delineamento}

Foi realizada uma pesquisa correlacional com uma postulação inicial de relações preditiva entre as variáveis investigadas. Para tanto, foi elaborado um modelo (Figura 1) de relação hipotética entre as variáveis dependentes (preferência por marca e por tipo de produto), a moderadora, valores humanos, e as antecedentes: fatores de importância dos critérios de decisão baseados em atributos dos produtos e a escolha anterior (último produto comprado). Caso os valores se configurem como moderadores, a moderação pode suprimir a escolha anterior, sendo então supressora.

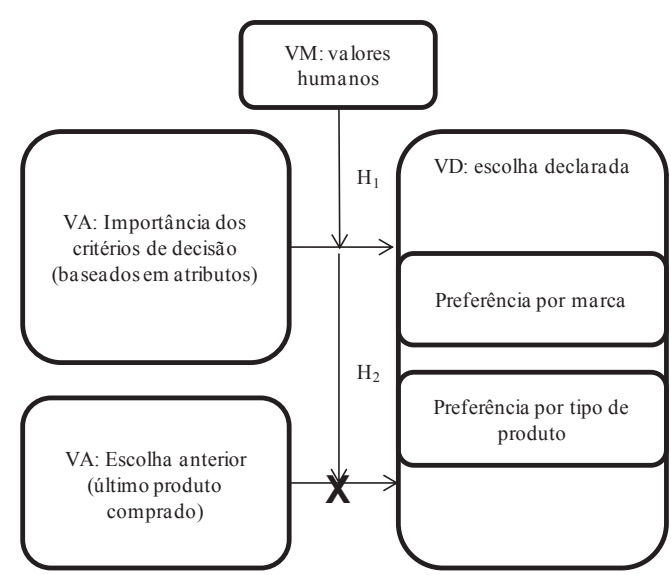

Figura 1. Modelo de Investigação 


\section{Definição operacional e instrumentos}

A preferência por marca de carro é o agrupamento de três verbalizações consecutivas das marcas de montadora de carro que o respondente escolheria para ser seu próximo veículo automotor. Se em três alternativas o consumidor relatasse que gostaria de ter duas ou três iguais, ele demonstra preferência pela marca. Similarmente, preferência pelo tipo de carro é o agrupamento de três verbalizações consecutivas dos modelos de carro categorizados em tipos, que o respondente escolheria para ser seu próximo veículo automotor, tais como: utilitário esportivo, sedan luxuoso e compacto luxuoso. Assim, se em três alternativas o consumidor relata que gostaria de ter dois ou três tipos iguais, ele demonstra preferência pelo tipo de carro.

As definições dos tipos de carro são: (1) utilitários esportivos, veículos com dois blocos, alto, e que permite ser utilizado fora da estrada (ex; Sportage, Ecosport, Tucson); (2) compactos luxuosos, veículo com dois blocos com porta mala reduzido com motores acima de 1.6 (ex; A3, Stilo, 307) e (3) sedans luxuosos, veículos com três blocos nítidos podendo o teto descer suavemente até a traseira do carro com motores acima de 1.6 (ex; Vectra, Corolla, Passat).

Utilizou-se o agrupamento fatorial de $1^{\text {a }}$ ordem dos valores humanos pessoais verbalizados pelos respondentes utilizando o IVS (Tamayo \& Schwartz, 1993). O instrumento apresenta 61 valores avaliados por uma escala de importância que varia de 1 (valores opostos aos meus valores) a 7 (valores de suprema importância). O IVS avalia os valores que são agrupados em 10 tipos motivacionais (Autodeterminação, Estimulação, Hedonismo, Realização, Poder, Segurança, Conformidade, Tradição, Benevolência e Universalismo) e duas dimensões bipolares (Autotranscendência/Autopromoção e Abertura à mudança/Conservadorismo) propostos teoricamente por Schwartz (1992).

A escolha anterior foi medida pela posse do último carro comprado. Foi registrada a compra do carro atualmente utilizado pelo respondente, categorizado pela marca da montadora e pelo tipo de carro. É uma variável comportamental e categórica de escolha anterior de veículo. Os critérios de decisão vieram dos fatores da importância dos atributos de carro. Ao todo eram 19 itens avaliados numa escala de 0 a 10, sendo 0 sem importância alguma e 10 extremamente importante. Utilizando a Análise dos Componentes Principais como método de extração, com rotação Promax e normalização Kaiser, os resultados sugeriram a presença de três fatores. Eles foram nomeados da seguinte maneira: (1) Importância do serviço da concessionária e da oferta de mercado, (2) Importância dos atributos de imagem do carro e (3) Importância dos atributos técnicos do carro.

\section{Amostragem}

A amostra foi composta por 209 sujeitos que responderam todos os instrumentos permitindo a análise para as marcas e os tipos de carro. Desses sujeitos, $60 \%$ eram consumidores que desembolsaram maior volume financeiro pela compra do carro utilizado, 52\% tinham carro zero quilômetro e $57 \%$ relatam que a pessoa que mais influenciou a compra do seu atual veículo foi algum parente próximo. Ressalta-se que $43 \%$ disseram ter sido ele próprio o maior influenciador da compra. Também, $55 \%$ eram do sexo masculino, $55 \%$ eram solteiros e $56 \%$ possuem curso superior completo, sendo que desses, $58 \%$ possuem ou estão em algum curso de pós-graduação. A idade média foi de 32 anos $(D P=11,41)$ e a renda familiar média mensal foi de $\mathrm{R} \$ 6.907,58(D P=3.944,35)$.

Muitos consumidores não apresentaram preferência por nenhuma marca de montadora $(73,2 \%)$. O restante apresentou por alguma, sendo que as marcas mais representativas foram: General Motors (10,5\%), Volkswagen (5,7\%), Fiat (3,3\%) e Ford (2,9\%). Alguns consumidores apresentaram preferência (duas ou três alternativas de três) pelo tipo de carro sedan luxuoso (14,9\%), compacto luxuoso (18\%) e utilitário esportivo $(10,0 \%)$. Os atributos com maior média foram: estabilidade do carro - segurança nas curvas em alta velocidade e largura de pneus (média $=8,60 ; D P=1,77$ ), qualidade das peças - acabamento interno ou durabilidade mecânica (média = 8,49; $D P=$ 1,58) e conforto -silencioso, ter ar condicionado e/ou direção macia (média $=8,48 ; D P=1,71$ ).

Alguns consumidores possuíam carro classificado como sedan luxuoso $(17,7 \%)$, compacto luxuoso $(16,0 \%)$ ou utilitário esportivo $(1,4 \%)$. Os tipos motivacionais com maiores médias foram, respectivamente: benevolência (média $=4,90$; $D P=0,8)$, autodeterminação $(4,9 ; D P=0,8)$ e hedonismo $(4,7$; $D P=1,1)$. O poder amostral (Cohen, 1992) para as regressões foi na ordem de 98\%, o suficiente para evitar o Erro Tipo 2.

\section{Procedimento de coleta e análise}

Os dados foram coletados em postos de gasolina. O aplicador do survey abordava os participantes e explicava que se tratava de uma pesquisa acadêmica sobre psicologia do consumidor. Os respondentes demoravam, em média, 30 minutos para preencher todo o questionário. Devido ao longo tempo, a melhor estratégia de coleta dos dados foi em filas de pré-lavagem de carro em postos de gasolina.

Foram feitas análises de regressão múltiplas sem (e com) termos interativos. Para a V.D., preferência por marca (Modelos 1 e 2), utilizou-se a logística binária. Como poucos sujeitos apresentaram preferência por marca, a escolha de duas ou três marcas foi codificada com código = 1 (preferência) e a escolha de uma ou nenhuma marca com o código 0 (sem preferência).

Já a preferência para cada tipo de carro (Modelos 3 e 4 para preferência por sedan luxuoso, Modelos 5 e 6 para preferência por compacto luxuoso e Modelos 7 e 8 para preferência por utilitário esportivo) teve maior amostra de preferência e permitiu realizar análise de regressão ordinal com função log-log negativa. Ela tem os mesmos pressupostos da regressão logística, com exceção que a variável dependente precisa ser ordinal e não dicotômica. A interpretação dela é similar à regressão múltipla normal, porém a fórmula é baseada em transformações logísticas. Ela utiliza a seguinte fórmula: $\operatorname{link}(\gamma \mathrm{ij})=\theta j-[\beta 1 \mathrm{xi} 1+\beta 2 \mathrm{xi} 2+\ldots+\beta$ pxiJ], onde link( ) é a função que liga as categorias ordenadas, neste caso log-log negativa, 
үij é a probabilidade cumulativa de cada categoria para cada sujeito, $\theta \mathrm{j}$ é o limiar para cada categoria ordenada, xi1...xiJ são os valores dos preditores para cada sujeito e $\beta 1 \ldots \beta$ p é o coeficiente da regressão. Assim, tanto as regressões logísticas quanto as ordinais demonstram probabilidades de ocorrência em cada nível da variável dependente. Elas são demonstradas nos gráficos da seção resultados.

\section{Resultados}

Inicialmente são demonstrados os resultados referentes à preferência por marca (Modelos 1 e 2), preferência por sedan luxuoso (Modelos 3 e 4), preferência por compacto luxuoso (Modelos 5 e 6) e finalmente preferência por utilitário esportivo (Modelos 7 e 8).Os modelos ímpares são aqueles sem os termos interativos e os modelos pares com os termos interativos. Para facilitar a leitura, apenas as estimativas e erros padrões das variáveis significativas são demonstrados nos modelos interativos.

Nas Tabelas 1 e 2, observa-se que os valores humanos raramente influenciavam diretamente as preferências (ex; valor Segurança para preferência por marcas), mas interagiram com a importância atribuída aos critérios de decisão (modelos pares), tanto para preferência por marcas quanto para preferência por tipos de produto (carros sedans luxuosos, compactos luxuosos e utilitários esportivos - SUV). Todas as análises de regressão com termos interativos incluídos apresentaram bons ajustes (-2 log likelihood significativos para $\mathrm{p} \leq 0,01)$ e $R^{2}$ Nagelkerke altos (entre $75,5 \%$ a $82,9 \%$ ), melhores do que os modelos sem interação, com baixas variâncias explicadas.

Além disso, nos modelos sem interação, a escolha anterior é preditiva sobre a preferência por marca, sedan luxuoso e compacto luxuoso. Em específico, após os consumidores terem escolhido comportamentalmente (possuem) a marca Fiat e Volkswagen, diminui-se a probabilidade de preferirem essas marcas, independente dos valores humanos e importância dos critérios de decisão. Quando possuem modelos de carro que se enquadram como sedans, luxuosos ou não luxuosos, aumenta-se a probabilidade de preferirem os tipos de carro sedans luxuosos, independente dos valores humanos e importância dos critérios de decisão. Relação similar é encontrada para compactos luxuosos (se possuem um compacto luxuoso, aumenta-se a probabilidade de preferir o tipo compacto luxuoso). Relações significativas não foram encontradas para os utilitários esportivos.

Entretanto, a última marca e o tipo de produto adquirido deixam de ser preditores quando são inseridos os termos de interação entre valores humanos e importância dos critérios de decisão (Modelos 2, 4, 6 e 8). Logo, quando há moderação dos valores humanos, a inércia da escolha anterior é suprimi$\mathrm{da}$, favorecendo a escolha da nova marca ou tipo de produto.

Assim, os valores humanos - Autodeterminação, Benevolência e Realização - interagiram positivamente com a importância dos critérios de decisão para preferência por marcas. Os valores humanos - Realização, Autodeterminação e Benevolência - também interagiram positivamente com a importância dos critérios de decisão para preferência por sedans luxuosos. O valor humano - Estimulação - interagiu positivamente com a importância dos critérios de decisão para preferência por carros compactos luxuosos. Os valores humanos - Poder, Autodeterminação, Benevolência, Realização e Segurança - interagiram positivamente com a importância dos critérios de decisão para preferência por carros utilitários esportivos.

Houve também interações negativas apenas para os tipos de produto. Os valores humanos - Tradição, Segurança e Poder - interagiram negativamente com a importância dos critérios de decisão para preferência por sedans luxuosos. O valor humano - Tradição - interagiu negativamente com a importância dos critérios de decisão para preferência por carros compactos luxuosos. Os valores humanos - Realização, Hedonismo, Autodeterminação, Universalismo e Conformidade- interagiram negativamente com a importância dos critérios de decisão para preferência por carros utilitários esportivos.

A Figura 2 demonstra alguns exemplos dessas moderações exercidas pelos valores humanos na relação entre a importância dos critérios de decisão e a preferência por marcas (Gráficos A e B), preferência por tipo de sedans luxuosos (Gráficos C e D) e preferência por tipo de utilitários esportivos (Gráficos E e F). Observa-se, como um todo, que a depender dos níveis endossados do valor humano, a relação da importância dos critérios de decisão sobre as probabilidades de preferência por marcas e tipos de produto são alteradas.

\section{Discussão}

O resultado geral evidencia que os valores moderam a relação preditiva da importância dos critérios de decisão sobre a preferência por tipos de produto (e/ou marca), corroborando $H_{1}$, e suprimem a influência da escolha anterior na preferência declarada, corroborando também $H_{2}$. No geral, os resultados demonstram o papel das motivações nas trocas ou manutenções de marcas ou de tipos de produto. Os valores humanos endossados incentivam a busca por escolhas que sejam mais compatíveis com as metas abstratas (Allen \& Ng, 1999; Verplanken \& Holland, 2002) por meio das decisões de consumo. Porém, ao atribuir maior peso de importância para alguns critérios de decisão e reduzir a importância de outros, os valores humanos influenciam a preferência de marcas e produtos por mecanismos indiretos de moderação. Isso oferece outra interpretação para os estudos de valores (Jesuíno et al., 2012; Torres \& Allen, 2009). 
Tabela 1

Resultado das Regressões para a Preferência por Marcas (Modelo 1 e 2) e Sedan Luxuoso (Modelo 3 e 4)

\begin{tabular}{|c|c|c|c|c|c|c|c|c|c|}
\hline & & & & & & & EDAN & UXUOSO & \\
\hline Variáveis & Mod & 01 & & 102 & & Moc & 103 & Mode & 104 \\
\hline & B & E.P. & B & E.P. & & B & E.P. & B & E.P. \\
\hline Atributos de concessionárias e mercado & $-0,02$ & 0,15 & - & - & Atributos de concessionárias e mercado & 0,15 & 0,10 & - & - \\
\hline Atributos da imagem do carro & $-0,19$ & 0,11 & - & - & Atributos da imagem do carro & $-0,03$ & 0,08 & $-5,19^{b}$ & 2,06 \\
\hline Atributos técnicos do carro & 0,02 & 0,16 & - & - & Atributos técnicos do carro & $-0,03$ & 0,11 & $5,61^{\mathrm{a}}$ & 2,75 \\
\hline Poder & $-0,17$ & 0,22 & - & - & Poder & 0,21 & 0,15 & - & - \\
\hline Realização & $-0,24$ & 0,25 & - & - & Realização & $-0,20$ & 0,16 & $-10,95^{b}$ & 3,88 \\
\hline Hedonismo & 0,10 & 0,19 & - & - & Hedonismo & $-0,10$ & 0,12 & - & - \\
\hline Estimulação & 0,22 & 0,16 & - & - & Estimulação & $-0,12$ & 0,11 & - & - \\
\hline Autodeterminação & $-0,09$ & 0,29 & - & - & Autodeterminação & 0,09 & 0,2 & $18,47^{\mathrm{b}}$ & 6,67 \\
\hline Universalismo & $-0,04$ & 0,26 & - & - & Universalismo & $-0,27$ & 0,17 & - & - \\
\hline Benevolência & $-0,02$ & 0,35 & - & - & Benevolência & 0,19 & 0,23 & - & - \\
\hline Tradição & $-0,02$ & 0,2 & - & - & Tradição & $-0,07$ & 0,14 & $8,45^{b}$ & 2,98 \\
\hline Conformidade & 0,14 & 0,25 & - & - & Conformidade & $-0,01$ & 0,16 & - & - \\
\hline Segurança & $0,71^{\mathrm{a}}$ & 0,32 & - & - & Segurança & $-0,06$ & 0,2 & - & - \\
\hline Última marca comprada (Fiat) & $-1,24^{b}$ & 0,29 & - & - & Posse de compacto luxuoso & $-0,22$ & 0,71 & - & - \\
\hline Última marca comprada (Volkswagen) & $-1,27^{b}$ & 0,38 & - & - & Posse de picape & $-19,18$ & 0,54 & - & - \\
\hline Última marca comprada (Ford) & $-0,26$ & 0,1 & - & - & Posse de sedan luxuoso & $1,19^{b}$ & 0,27 & - & - \\
\hline Última marca comprada (Outros) & $-0,75$ & 0,41 & - & - & Posse de sedan não luxuoso & $0,97^{\mathrm{b}}$ & 0,39 & - & - \\
\hline Última marca comprada (Renault) & $-0,69$ & 0,87 & - & - & Posse de utilitário esportivo & 0,24 & 0,99 & - & - \\
\hline Última marca comprada (Peugeot) & $-0,56$ & 0,63 & - & - & Posse de minivan & 0,21 & 0,50 & - & - \\
\hline Última marca comprada (General Motors) & 0 refe & ncia) & - & - & Posse de compacto popular & 0 (refe & ência) & - & - \\
\hline Atributos de concessionárias e mercado * & inação & & $5,98^{\mathrm{b}}$ & 0,78 & Atributos de concessionárias e mercado * Realização & & & $1,33^{\mathrm{b}}$ & 0,39 \\
\hline Atributos da imagem do carro * Autodetern & & & $2,64^{a}$ & 1,23 & Atributos de concessionárias e mercado * Tradição & & & $-0,96^{b}$ & 0,30 \\
\hline Atributos da imagem do carro * Benevolên & & & $1,91^{\mathrm{a}}$ & 0,95 & Atributos da imagem do carro * Poder & & & $-0,67^{\mathrm{a}}$ & 0,27 \\
\hline Atributos da imagem do carro * Realização & & & $25,3^{b}$ & 0,68 & Atributos da imagem do carro * Benevolência & & & $0,70^{\mathrm{a}}$ & 0,33 \\
\hline & & & & & Atributos da imagem do carro * Segurança & & & $-1,30^{b}$ & 0,39 \\
\hline & & & & & Atributos técnicos do carro * Autodeterminação & & & $1,81^{b}$ & 0,72 \\
\hline$R^{2}$ Nagelkerke & 36,7 & & & & $R^{2}$ Nagelkerke & & & 77,8 & \\
\hline Ajuste do modelo (- 2 Log likelihood) & 89, & & & & Ajuste do modelo (-2 Log likelihood) & & & & \\
\hline
\end{tabular}

${ }^{\mathrm{a}} p \leq 0,05 ;{ }^{\mathrm{b}} p \leq 0,01$ 
Tabela 2

Resultado das Regressões para a Preferência por Compacto Luxuoso (Modelo 5 e 6) e Utilitário Esportivo (Modelo 7 e 8)

\begin{tabular}{|c|c|c|c|c|c|c|c|c|c|}
\hline & & mpac & luxuos & & & & tilitário & esporti & \\
\hline Variáveis & Moc & & Mod & 106 & Variáveis & Moc & 107 & Moc & 108 \\
\hline & B & E.P. & B & E.P. & & B & E.P. & B & E.P. \\
\hline Atributos de concessionárias e mercado & $-0,16$ & 0,09 & - & - & Atributos de concessionárias e mercado & 0,12 & 0,09 & - & - \\
\hline Atributos da imagem do carro & $0,15^{\mathrm{a}}$ & 0,08 & - & - & Atributos da imagem do carro & $-0,07$ & 0,07 & - & - \\
\hline Atributos técnicos do carro & $-0,16$ & 0,11 & - & - & Atributos técnicos do carro & $0,22^{\mathrm{a}}$ & 0,11 & $-7,23^{b}$ & 2,28 \\
\hline Poder & 0,19 & 0,15 & - & - & Poder & $-0,21$ & 0,15 & - & - \\
\hline Realização & 0,09 & 0,16 & - & - & Realização & 0,09 & 0,16 & - & - \\
\hline Hedonismo & $-0,02$ & 0,12 & $3,60^{\mathrm{a}}$ & 1,85 & Hedonismo & 0,08 & 0,12 & - & - \\
\hline Estimulação & 0,02 & 0,10 & - & - & Estimulação & 0,02 & 0,1 & - & - \\
\hline Autodeterminação & $-0,15$ & 0,19 & - & - & Autodeterminação & $-0,21$ & 0,18 & - & - \\
\hline Universalismo & $-0,27$ & 0,16 & - & - & Universalismo & $-0,04$ & 0,16 & - & - \\
\hline Benevolência & 0,21 & 0,21 & - & - & Benevolência & 0,16 & 0,21 & $-6,60^{\mathrm{a}}$ & 2,79 \\
\hline Tradição & $-0,03$ & 0,13 & - & - & Tradição & $-0,19$ & 0,13 & - & - \\
\hline Conformidade & 0,17 & 0,16 & - & - & Conformidade & $-0,26$ & 0,15 & $5,17^{\mathrm{a}}$ & 2,34 \\
\hline Segurança & $-0,06$ & 0,20 & - & - & Segurança & 0,17 & 0,20 & - & - \\
\hline Posse de compacto luxuoso & $1,64^{b}$ & 0,40 & - & - & Posse de compacto luxuoso & 0,02 & 0,49 & - & - \\
\hline Posse de picape & $-19,24$ & 0,00 & - & - & Posse de picape & $-0,30$ & 0,99 & - & - \\
\hline Posse de sedan luxuoso & $-0,23$ & 0,32 & - & - & Posse de sedan luxuoso & $-0,16$ & 0,31 & - & - \\
\hline Posse de sedan não luxuoso & $-0,98$ & 0,62 & - & - & Posse de sedan não luxuoso & $-0,58$ & 0,53 & - & - \\
\hline Posse de utilitário esportivo & 1,23 & 0,72 & - & - & Posse de utilitário esportivo & $-0,05$ & 1,01 & - & - \\
\hline Posse de minivan & $-0,27$ & 0,50 & - & - & Posse de minivan & $-0,13$ & 0,45 & - & - \\
\hline Posse de compacto popular & 0 (refe & ncia) & - & - & Posse de compacto popular & 0 (ref & ência) & - & - \\
\hline Atributos da imagem do carro * Tradição & & & $-0,53^{b}$ & 0,19 & Atributos de concessionárias e mercado * Poder & & & $0,56^{b}$ & 0,23 \\
\hline Atributos técnicos do carro * Estimulação & & & $0,49^{b}$ & 0,19 & $\begin{array}{l}\text { Atributos de concessionárias e mercado *Reali- } \\
\text { zação }\end{array}$ & & & $-0,56^{a}$ & 0,24 \\
\hline & & & & & $\begin{array}{l}\text { Atributos de concessionárias e mercado * Autode- } \\
\text { terminação }\end{array}$ & & & $-0,80^{\mathrm{a}}$ & 0,34 \\
\hline & & & & & Atributos da imagem do carro * Hedonismo & & & $-0,39^{a}$ & 0,17 \\
\hline & & & & & Atributos da imagem do carro * Universalismo & & & $-0,48^{\mathrm{a}}$ & 0,20 \\
\hline & & & & & Atributos técnicos do carro * Realização & & & $0,92^{b}$ & 0,35 \\
\hline & & & & & Atributos técnicos do carro * Autodeterminação & & & $1,05^{\mathrm{a}}$ & 0,48 \\
\hline & & & & & Atributos técnicos do carro * Benevolência & & & $1,16^{\mathrm{b}}$ & 0,39 \\
\hline & & & & & Atributos técnicos do carro * Conformidade & & & $-0,69^{a}$ & 0,30 \\
\hline & & & & & Atributos técnicos do carro * Segurança & & & $1,08^{\mathrm{b}}$ & 0,38 \\
\hline$R^{2}$ Nagelkerke & & & 75 & & $R^{2}$ Nagelkerke & & & & \\
\hline Ajuste do modelo (-2 Log likelihood) & 38 & & 183 & & Ajuste do modelo (-2 Log likelihood) & & & & \\
\hline
\end{tabular}

${ }^{\mathrm{a}} p \leq 0,05 ;{ }^{\mathrm{b}} p \leq 0,01$ 

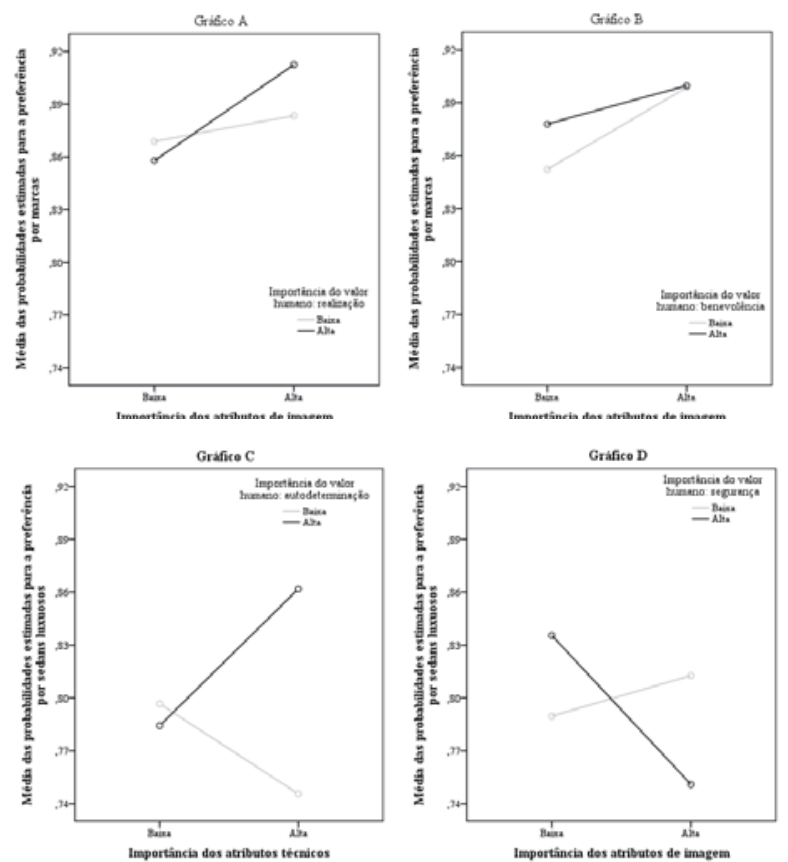

Grafico $\mathrm{E}$
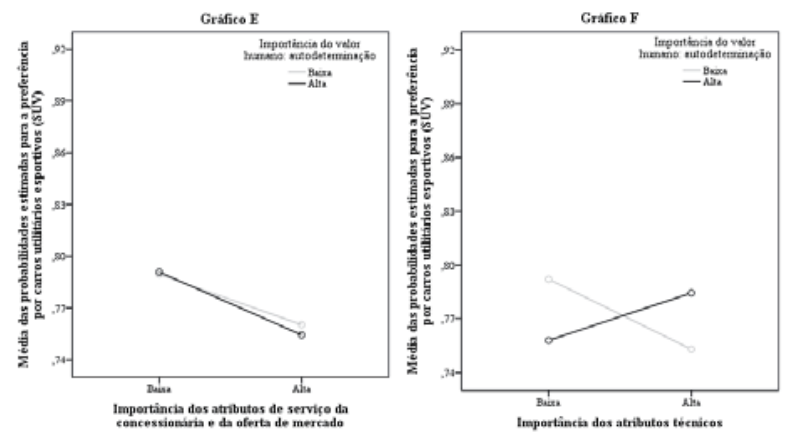

Figura 2. Exemplos de Gráficos de Interação dos Valores Humanos com os Critérios de Decisão

Retirando os impeditivos das situações de escolha, os valores humanos agem fortemente como contextualizadores pessoais das decisões de consumo, influenciando a preferência por produtos ou marcas. Porém, não parecem agir como causadores dos comportamentos (Rohan, 2000). Logo, os valores humanos são metas pessoais percebidas direcionadas às ações futuras (Schwartz, 1992), porém refletem história de aprendizagem mediada pela sociedade (Foxall, 2005). O indivíduo aprende o que deve ser perseguido no meio social (metas baseadas em reforçadores sociais no nível individual de análise) e suas decisões passam a ser balanceadas por elas. A depender das interações valores-decisões, a preferência por uma alternativa de ação se torna mais provável.

Especificamente, os valores de Poder com interação da importância dos critérios de decisão referentes aos atributos de serviço da concessionária e oferta de mercado influenciam positivamente a preferência por SUV, e com interação aos critérios referentes à imagem do carro influenciam negativamente a preferência por sedans luxuosos. A dominância sobre recursos (Schwartz et al., 2012), uma das subdimensões dos valores de Poder, podem levar à preferência por SUV se os consumidores julgarem serem importantes as opções de preço do carro, manutenção e reparo. Os indivíduos podem perceber maior dominância se tiverem condições de comprar e manter o carro e, assim, comprariam uma SUV. Por outro lado, consumidores que valorizam status podem reduzir a preferência por sedans luxuosos existentes no Brasil porque, em relação aos modelos de carro estrangeiros, eles são aparentemente inferiores, não oferecem prestígio, nem mesmo ao adquirir a imagem demonstra dominância sobre os outros.

Os valores de Realização com interação da importância dos critérios de decisão referentes aos atributos de serviço da concessionária e oferta de mercado influenciam positivamente a preferência por sedans luxuosos e negativamente a preferência por SUV. Já com interação aos critérios referentes aos atributos técnicos do produto e aqueles referentes à imagem do produto influenciam positivamente e respectivamente a preferência por SUV e a marca da montadora. A possibilidade de demonstração de sucesso na vida (Schwartz, 1992) pode explicar porque preferem sedans luxuosos, SUV e marcas específicas de montadoras. A importância atribuída às decisões sobre as condições de mercado e imagem podem salientar que não é tão fácil assim adquirir esses carros. Assim aqueles que têm condições de adquirir, ficam satisfeitos por terem conseguido; demonstram competência. Por outro lado, podem inibir a preferência por SUV por demonstrar não ser competentes para obtê-los, devido às condições não benéficas do mercado - geralmente SUVs são os modelos mais caros que existem no mercado brasileiro.

Os valores de Hedonismo com interação da importância dos critérios de decisão referentes à imagem do produto influenciam negativamente a preferência por SUV. Indivíduos que atribuem pouca importância ao design aumentam a probabilidade de preferir SUVs, se o consumidor tiver um alto senso de gratificação (Schwartz, 1992). A imagem não parece ser um critério fundamental para esses consumidores e criam aversão a esses modelos.

Os valores de Estimulação com interação da importância dos critérios de decisão referentes aos atributos técnicos do produto influenciam positivamente a preferência por compactos luxuosos. Os compactos luxuosos por terem vários itens de desempenho do motor e inovações tecnológicas podem ser a primeira grande aquisição de um consumidor jovem, o que demonstraria uma situação de desafio (Schwartz et al., 2012). Logo, o valor de estimulação salienta que esses atributos propiciam a novidade em obtê-los.

Os valores de Autodeterminação com interação da importância dos critérios de decisão referentes aos atributos de serviço da concessionária e oferta de mercado influenciam negativamente a preferência por SUV e positivamente a preferência por marcas. Com interação da importância atribuída à imagem do produto, esses valores influenciam positivamente a preferência por marcas do carro. Já com interação dos critérios referentes aos atributos técnicos do produto também 
influenciam positivamente a preferência por sedans luxuosos e SUV. Como um todo, a liberdade de pensamento propiciada por aqueles que endossam esse valor (Schwartz et al., 2012) permitem que a importância dos critérios seja benéfica para a preferência de marcas e produtos, com exceção quando salientam os serviços de concessionárias e os preços de mercado dos modelos SUV. Esses critérios podem demonstrar que os consumidores não têm tantas escolhas livres na compra de um carro, reduzindo a probabilidade de suas preferências.

Os valores de Universalismo com interação da importância dos critérios de decisão referentes à imagem do carro influenciam negativamente a preferência por SUV. A proteção à natureza (Schwartz et al., 2012) pode salientar que o uso desse tipo de carro denigre o meio ambiente. Os utilitários esportivos, na época dessa pesquisa, geralmente não apresentavam alternativas sustentáveis de combustível, sendo o consumo de gasolina ou diesel, aqueles que agridem mais o meio ambiente, os únicos possíveis. Como esse conhecimento se tornou reconhecido entre os brasileiros, os endossantes desse valor deixaram de preferir esses modelos de produtos.

Os valores de Benevolência com interação da importância dos critérios de decisão referentes à imagem das marcas influenciam positivamente a preferência por marcas e por sedans luxuosos. Já com interação aos critérios referentes aos atributos técnicos do produto influenciam também positivamente a preferência por SUV. Esse valor é benéfico à preferência por esses carros possivelmente pelos cuidados com a família (Schwartz, 1992; Schwartz, 1996), em especial, com as outras pessoas que são transportadas no veículo. Critérios de decisão sobre os atributos técnicos e sobre a imagem podem passar a impressão de bem estar para quem usufruir o veículo.

Os valores de Conformidade com interação da importância dos critérios de decisão referentes aos atributos técnicos do produto influenciam negativamente a preferência por SUV. As pessoas que seguem opiniões de outras pessoas ou não se sentem capazes de ter um carro com atributos tecnológicos ou potentes reduzem a preferência pelos utilitários esportivos, em especial quando endossam os valores de conformidade. As expectativas do que devem ter (e do que não devem) em meio social (Schwartz et al., 2012) podem inibir a busca por esses veículos através de decisões dos atributos técnicos.

Os valores de Tradição tanto com interação da importância dos critérios de decisão referentes aos atributos de serviço da concessionária e oferta de mercado quanto com interação da importância dos critérios de imagem do produto influenciam negativamente e respectivamente a preferência por sedans luxuosos e compactos luxuosos. Aqueles indivíduos que atribuem pouca importância para a imagem e as condições de mercado têm maior preferência por carros mais caros (luxuosos no mercado brasileiro), se endossarem valores de aceitação dos costumes e confiança. Por aceitar as condições sociais (Schwartz et al., 2012), eles estão menos suscetíveis às decisões de aparência e preço e optam por esses produtos, possivelmente devido às compras familiares anteriores.
Finalmente, os valores de Segurança com interação da importância dos critérios de decisão referentes à imagem do produto influenciam negativamente a preferência por sedans luxuosos, enquanto que com interação da importância dos critérios de decisão referentes aos atributos técnicos do produto influenciam positivamente a preferência por SUV. Quando consumidores endossam valores de proteção (Schwartz et al., 2012) e atribuem muita importância para a aparência do produto podem perceber que os carros luxuosos não são seguros, poderiam assim, ser mais visados para o roubo. Isso inibe suas escolhas para esses consumidores. Por outro lado, os atributos técnicos - ex: segurança ao dirigir - aumentam as chances de escolhas dos utilitários esportivos. Assim, os valores oferecem contextos pessoais para as decisões.

Ao moderar a relação da importância dos critérios de decisão sobre a preferência por tipos de produto (e/ou marca), os valores inibem a inércia das escolhas anteriores sobre a preferência. As preferências decorrentes dos mecanismos de hábitos (Foxall, 2005), portanto, são eliminados e a pessoa passa a perceber que os produtos ou marcas podem ser meios de alcance de metas mais congruentes com os valores endossados (Allen \& Ng, 1999), a depender de suas decisões. A evidência demonstrada nesta presente pesquisa pode ser devido ao produto escolhido. Os veículos são meios de condução públicos e caros na sociedade brasileira. Em alguns casos, podem ser sonhos de consumo, contendo significado de sua utilidade ou simbolismo. Assim, as decisões de sua aquisição não são despercebidas e podem expressar valores endossados por quem os escolher.

\section{Considerações finais}

Os resultados podem direcionar um novo caminho de pesquisa na área de valores humanos que testem moderação/ supressão. Ao superar algumas limitações metodológicas e erros de concepção, os valores humanos são contextualizadores pessoais da busca de escolhas, possivelmente devido à aprendizagem em meio social sobre o que se deve ter como metas na sociedade. Por sua vez, alguns itens de consumo são meios de alcançá-los. Apesar de este estudo ter sido realizado em apenas uma situação de escolha de um produto, com múltiplas marcas e tipos, futuras pesquisas podem testar outras situações de escolha de produtos ou mesmo testar fora da área de consumo, se existe o papel moderador/ supressor dos valores humanos. Assim, pesquisadores podem encontrar resultados que tragam generalização com boa variância explicada e deem luz para relacionar valores às escolhas.

\section{Referências}

Ajzen, I. (2012). Theory of planned behavior. In P. Van Lange, A. Kruglanski, \& E. Higgins (Orgs.), The handbook of theories of social psychology (Vol. 1, pp. 438-459). Londres: Sage Publications.

Alfinito, S. (2009). A influência de valores humanos e axiomas sociais na escolha do consumidor: Uma análise comparativa aplicada à educação superior (Tese de doutorado não publicada). Universidade de Brasília, Brasília, DF. 
Allen, M. W., \& Ng, S. H. (1999). The direct and indirect influences of human values on product ownership. Journal of Economic Psychology, 20(1), 5-39. doi: 10.1016/S0167-4870(98)00041-5

Bettman, J. R., Johnson, E. J., \& Payne, J. W. (1991). Consumer decision making. In T. S. Robertson \& H. H. Kassarjian (Orgs.), Handbook of consumer behavior (pp. 50-84). Englewood Cliffs, NJ: Prentice-Hall.

Bilsky, W. (2000). Motives and values: Towards a taxonomic integration of two psychological construct. Westfäsliche Wilhelms- Universität Münster.

Feather, N. T. (1988). From values to actions: Recent applications of the expectancy-value model. Australian Journal of Psychology, 40(2), 105-124. doi: 10.1080/00049538808259076

Ferreira, M. C, Fernandes, H., \& Silva, A. P. C. (2009). Valores organizacionais: Um balanço da produção nacional do período de 2000 a 2008 nas áreas de administração e psicologia. Revista de Administração Mackenzie, 10(3), 84-100. doi: 10.1590/S1678-69712009000300006

Fishbein, M., \& Ajzen, I. (1975). Belief, attitude, intention and behavior: An introduction to theory and research. MA: Addison-Wesley

Fortes, K. (2006). Relação entre valores pessoais e preferência por categorias de filmes (Dissertação de mestrado não publicada). Universidade de Brasília, Brasília, DF.

Foxall, G. (2005). Understanding consumer choice. Nova Iorque: Palgrave Macmillan

Gollwitzer, P. M. (1996). The volitional benefits of planning. In P. M. Gollwitzer \& J. A. Bargh (Orgs.), The psychology of action: Linking cognition and motivation to behavior (pp. 287-312). Nova Iorque: Guilford

Gouveia, V. V., Milfont, T. L., Fischer, R., \& Coelho, J. A. P. (2009). Teoria funcionalista dos valores humanos: Aplicações para organizações. Revista de Administração Mackenzie, 10(3), 34-59. doi: 10.1590/S167869712009000300004

Hofstede, G. H. (2001). Culture's consequences: Comparing values, behaviors, institutions and organizations across nations. Londres: Sage.

Jesuíno, J. C., Torres, C. V., \& Teixeira, M. L. M. (2012). Avanços teóricos e metodológicos em valores humanos e gestão: Uma introdução ao fórum. Revista de Administração Mackenzie, 13(3), 14-17. doi: 10.1590/S167869712012000300002

Jose, P. E. (2012). Doing statistical mediation and moderation. Nova Iorque: Guilford Press.

Kahle, L. R., \& Kennedy, P. (1989). Using the list of values (LOV) to understand consumers. Journal of Consumer Marketing, 6(3), 5-12. doi: 10.1108/ EUM0000000002549

Kluckhohn, F. R., \& Strodtbeck, F. L. (1961). Variations in value orientations. Evanston: Row Peterson and Company.

Ma, Y. J., \& Lee, H. H. (2012). Understanding consumption behaviors for fair trade non-food products: Focusing on self-transcendence and openness to change values. International Journal of Consumer Studies, 36(6), 622-634. doi: 10.1111/j.1470-6431.2011.01037.x

Maduro-Abreu, A., \& Brasil, A. C. P. Jr. (2013). Desvelando a relação entre ideologia, valores do indivíduo e estilo de consumo. Ciências Sociais Unisinos, 49(3), 222-236.

Payne, J. W., Bettman, J. R., \& Johnson, E. J. (1992). Behavioral decision research: A constructive processing perspective. Annual Review of Psychology, 43, 87-131. doi: 10.1146/annurev.ps.43.020192.000511

Rokeach, M. (1973). The nature of human values. Nova Iorque: Free press.

Rohan, M. J. (2000). A rose by any name? The values construct. Personality and Social Psychology Review, 4(3), 255-277. doi: 10.1207/ S15327957PSPR0403_4

Schwartz, S. H. (1992). Universals in the content and structure of values: Theoretical advances and empirical tests in 20 countries. In M. P. Zana (Org.), Advances in Experimental Social Psychology (Vol. 24, pp.1-65). San Diego: Academic.

Schwartz, S. H. (1996). Value priorities and behavior: Applying a theory of integrated value systems. In C. Seligman, J. M. Olson, \& M. P. Zanna
(Orgs.), Psychology of values: The Ontario symposium (Vol. 8, pp. 1-26). Nova Jersey: Lawrence Erlbaum Associate.

Schwartz, S. H. (2011). Studying values: Personal adventure, future directions. Journal of Cross-Cultural Psychology, 42(2), 307-319. doi: $10.1177 / 0022022110396925$

Schwartz, S. H., Cieciuch, J., Vecchione, M., Davidov, F., Fischer, R., Beierlein, C., ..., Konty, M. (2012). Refining the theory of basic individual values. Journal of Personality and Social Psychology, 103(4), 663-688. doi: 10.1037/ a0029393

Tamayo, A., \& Porto, J. B. (2005). Valores e comportamento nas organizações. Rio de Janeiro: Vozes.

Tamayo, A., \& Schwartz, S. (1993). Estrutura motivacional dos valores humanos. Psicologia: Teoria e Pesquisa, 9(2), 329-348.

Torres, C. V., \& Allen, M. W. (2009). Human values and consumer choice in Australia and Brazil. Psicologia: Teoria e Pesquisa, 25(4), 489-497. doi: 10.1590/S0102-37722009000400004

Verplanken, B., \& Holland, R. W. (2002). Motivated decision making: Effects of activation and self centrality of values on choices and behavior. Journal of Personality and Social Psychology, 82(3), 434-447. doi: 10.1037/00223514.82.3.434 
Rafael Barreiros Porto, Doutor em Ciências do Comportamento (2009) pela Universidade de Brasília UnB, é Professor Adjunto na Universidade de Brasília - UnB. Endereço para correspondência: Programa de Pós Graduação em Administração da Universidade de Brasília. Campus Universitário Darcy Ribeiro, Prédio da FACE. Telefone: 55 (61) 3107-0759. E-mail: rafaelporto@unb.br

Cláudio V. Torres, Ph.D. em Psicologia Organizacional/Industrial pela California School of Professional Psychology - San Diego, CA, EUA (1999), Pós-doutorado em Marketing pela Griffith University Brisbane, Austrália (2003), Pós-doutorado em Psicologia Transcultural pela Sussex University - Brighton, Inglaterra (2009), Pós-doutorado em Pesquisa Intercultural e Valores Humanos pela Universidade Hebraica de Israel - Jerusalém, Israel (2013), é Professor Associado na Universidade de Brasília - UnB. E-mail: claudio.v.torres@gmail.com 